\title{
INTRODUCTION TO THE SYMPOSIUM ON GLOBAL PLASTIC POLLUTION
}

\author{
Donald McRae
}

Perhaps because of the shadow cast by the issue of climate change, the problem of global plastic pollution has not received the attention it deserves. Yet in many respects it poses equally intractable challenges to the world community in terms of both its environmental effects and its potential for regulation. And, like climate change, it pits activity that society has treated as enormously beneficial against consequences which have the potential to be environmentally disastrous. The use of plastic in its variety of forms has become deeply embedded in human culture, from its obvious use in packaging of consumer goods and in electronic equipment to its use in the construction industry and the manufacture of motor vehicles, as well as in heavy industry. And the harm from plastic is less obvious because it is diverse; harm may result from the fossil fuel extraction for the plastic feedstock, the manufacture or use of plastic products, or the ultimate deposit of waste in landfills or the oceans. In the case of the oceans, it takes exposés from the National Geographic ${ }^{1}$ to bring the harm from plastic waste to public attention. But waste is only the end result of a lifecycle that can cause harm all along the way. This symposium addresses different aspects of the regulation of global plastic pollution, from principles of environmental law more generally to the treaty regimes whose provisions might be invoked either directly or by analogy. The essays draw a picture of the state of global plastic pollution, pertinent aspects of international law, and potential legal solutions.

The diverse nature of plastic pollution provides a particular challenge to regulation. Waste is not the only harm from plastic, and treating plastic exclusively as a waste-management problem ignores the impact of the whole lifecycle of plastic products. It masks the central point that dealing with the manufacture of plastic products is a critical first step in dealing with waste. In short, it is not possible to deal with global plastic pollution without dealing with the "upstream" stage of plastic production. Effective regulation involves the regulation of activities within states, the regulation of the transport of products and plastic waste between states, and the regulation of the deposit of this waste into the oceans. Ocean pollution from plastics is largely from land-based sources.

How, then, do we approach the regulation of this complex issue? It is a characteristic of most international legal regimes that while they deal adequately with the problems of the past, they are often less effective at dealing with the problems that arise in the future. The 1982 UN Convention on the Law of the Sea was forward-looking for its time in its provisions on the protection of the marine environment and its imposition of obligations regarding pollution of the oceans from land-based sources. But it did not have plastic pollution in mind. The Basel Convention on the Control of Transboundary Movements of Hazardous Wastes and Their Disposal ${ }^{2}$ did not originally include plastics as hazardous waste. And the General Agreement on Tariffs and Trade's Article XXIV's exception for trade-restricting environmental protection measures was drafted well before plastics pollution became an issue.

* Emeritus Professor, University of Ottawa.

${ }^{1}$ Laura Parker, We Made Plastic. We Depend on It. Now We are Drowning in It, NAT’L GeOgraphic (June 2018).

2 Basel Convention on the Control of Transboundary Movements of Hazardous Wastes and Their Disposal, May 5, 1992,1673 UNTS 67.

(C) Donald McRae 2020. This is an Open Access article, distributed under the terms of the Creative Commons Attribution licence 
In recent years, however, international attention has started to focus on global plastics pollution. The 2012 United Nations Conference on Sustainable Development identified plastic as part of the marine pollution negatively affecting the oceans. ${ }^{3}$ Since then, the UN Environment Programme (UNEP) has emerged as an important forum of activity. In 2014, the UN Environment Assembly (UNEA) adopted a resolution on marine plastics and microplastics. This led to a concentration by UNEA on marine plastic pollution, including a comprehensive study in 2018, "Combating Marine Plastic Litter and Microplastics,"4 which assessed the effectiveness of international, regional, and sub-regional approaches and strategies for dealing with marine plastic pollution. Current work in UNEP is focused on the Ad Hoc Open-Ended Expert Group on Marine Litter and Microplastics, ${ }^{5}$ which was established to examine the barriers to and options for combating marine plastic litter and microplastics from all sources, especially land-based sources.

These efforts occur against a backdrop of international regulation that is currently characterized by fragmentation and a piecemeal treatment of different aspects of the problem. A 2019 amendment to the Basel Convention Annexes includes certain plastics as hazardous waste. There are conventions relating to vessel source pollution or dumping at sea and regional fisheries conventions which also are concerned with pollution of the seas. There are also regional seas conventions that contain obligations regarding land-based sources of pollution, which include plastic materials. There is no single international legal regime for plastic pollution.

But, should there be such a regime? And if there should be, what should it look like and how should it be structured? And if no comprehensive legal regime is necessary or feasible, what law needs to be developed by treaty or otherwise to address the plastics problem more directly? When lawyers try to create something new, they look at existing models, at analogies. But what is the correct analogy here? Is the problem posed by global plastics pollution simply the climate change problem written narrowly? Or, is the analogy more properly that of ozone depletion? What are the existing customary rules of international law or principles that might be relevant? Can they be applied to these new circumstances? What are the relevant treaty regimes that can apply in whole or in part to these circumstances?

The essays in this symposium engage in a dialogue on global plastic pollution and suggest solutions for these regulatory challenges. They set the stage for further comprehensive and systematic treatment by others of this critical global problem of both the land and sea environments.

Leslie-Anne Duvic-Paoli, a Lecturer at The Dickson Poon School of Law, King's College London, looks at the prevention principle, a foundational principle of international environmental law, in its application to the regulation of global plastics pollution. ${ }^{6}$ She considers the principle's different manifestations as a prohibition against causing harm (the "no-harm principle") and a due diligence requirement. Both manifestations are ultimately found wanting as specific guidance in the regulation of plastic pollution, in large part because they have been developed with an eye toward other forms of transboundary harm and cannot readily be applied to a problem of the geographic and jurisdictional complexity that plastics present. Nevertheless, Duvic-Paoli observes that the prevention principle

${ }^{3}$ G.A. Res. 66/288, at para. 163 (July 27, 2012).

${ }^{4}$ UN Env't Assembly, Combating Marine Plastic Litter and Microplastics: An Assessment of the Effectiveness of Relevant International, Regional and Subregional Governance Strategies and Approaches - A Summary for Policymakers, UN Doc. UNEP/ AHEG/2018/1/INF3 (2018).

${ }^{5}$ The Group was established at the Third Session of the UN Environment Assembly. See UN Env't Assembly, Marine Litter and Microplastics, UN Doc. UNEP/EA.3/Res.7 (2018).

${ }^{6}$ See Leslie-Anne Duvic-Paoli, Fighting Plastics with Environmental Principles? The Relevance of the Prevention Principle in the Global Governance of Plastics, 114 AJIL Unbound 195 (2020). 
is frequently invoked in discussions of plastic pollution and has an important role to play as a powerful "policy idea."7 In this sense, the principle will continue to influence the development of regimes that deal with this issue.

Sabaa Ahmad Khan, a Senior Researcher at the University of Eastern Finland's Center for Climate Change, Energy and Environmental Law, considers the Basel Convention and its 2019 amendment treating plastic waste as hazardous waste. ${ }^{8}$ Khan suggests that the amendment, controversial in its adoption, raises problems of consistency in future interpretation by states, potential controversies over the evidentiary requirements for documentation of non-hazardous waste, and enforcement challenges. She contends that the problem remains one of "moving away from toxic materials in product design" and ensuring the responsibility of producers over the lifecycle of products.?

Sandrine Maljean-Dubois, a Director of Research at the French National Center for Scientific Research, and Benoit Mayer, an assistant professor at The Chinese University of Hong Kong, address the question of liability and compensation. ${ }^{10}$ They do this against the background that the UNEA's Ad Hoc Open-Ended Expert Group on Marine Litter and Microplastics recently decided that a liability and compensation scheme is "not a priority at this stage." 11 Problems in determining both liability and compensation arise from the complexity of plastic pollution: Who should be responsible_-producers, suppliers, or consumers, all of whom may be in different jurisdictions? And who is harmed and therefore should be entitled to compensation, since the harm is caused to the global commons? Similar questions may be asked about state responsibility and the obligation to compensate. Yet, there are benefits in developing a liability regime in that even without compensation it could foster the prevention of marine plastics pollution. Maljean-Dubois and Mayer suggest that a common fund might also be considered.

Elizabeth Kirk, a professor at the University of Lincoln, addresses the possibility of a plastics treaty drawing on the Montreal Convention on Substances That Deplete the Ozone Layer and the Paris Agreement on Climate Change as models. ${ }^{12}$ Under the former, states undertake specific commitments to eliminate the use of certain materials, while under the latter states commit to set targets for emission reduction or elimination and progressively revise them upward. Kirk argues that the nature of plastic pollution makes the Montreal approach more appropriate, as plastics are not like greenhouse gases which can be "naturally 'recycled' through photosynthesis and respiration." 13 But given that plastics are ubiquitous throughout the world, the idea of banning or eliminating them seems infeasible. Nor is recycling all plastic material realistic. Kirk thus contends that new cooperative measures are needed to address plastics production and the distribution of goods and remove legacy plastics.

These essays provide a rich framework for considering aspects of global plastic pollution, from the applicability of principles of customary international law to the drafting of a comprehensive treaty. The essays share a common sense of the urgency of the problem and the complexity of dealing with it. What they make clear is that much more attention to the issue has to be given by governments, and that any solution has to involve industry and civil society. The dialogue in this symposium is an important step in promoting that action.

\footnotetext{
${ }^{7}$ Id. at 198.

8 See Sabaa Ahmad Khan, Clearly Hazardous, Obscurely Regulated: Lessons from the Basel Convention on Waste Trade, 114 AJIL UNBOUND 200 (2020).

${ }^{9} I$ d. at 205.

${ }^{10}$ See Sandrine Maljean-Dubois \& Benoît Mayer, Liability and Compensation for Marine Plastic Pollution: Conceptual Issues and Possible Ways Forward, 114 AJIL UnBound 206 (2020).

${ }^{11}$ UN Env't Assembly, Report of the First Meeting of the Ad Hoc Open-Ended Expert Group on Marine Litter and Microplastics para. 88, UN Doc. UNEP/AHEG/2018/1/6 (June 19, 2018).

12 See Elizabeth A. Kirk, The Montreal Protocol or the Paris Agreement as a Model for a Plastics Treaty?, 114 AJIL UnBound 212 (2020).

${ }^{13} I d$. at 213.
} 